\title{
Pitch detackification with natural and modified talcs
}

\section{$\underline{\text { Antonio Tijero }}^{*}$, M. Concepción Monte, Julio Tijero and Angeles Blanco}

Chemical Engineering Department, Chemistry Faculty, Complutense University of Madrid, Avda. Complutense s/n 28040 Madrid, Spain. Tel. +34 9139442 50; Fax. +34 9139442 45. E-mail: atijero@quim.ucm.es

\section{SUMMARY}

Pitch deposition in the pulp or in different parts of the manufacturing system can lead to a decrease in the quality of the final paper produced and to manufacturing efficiency problems. Tackiness is the property of pitch which related to the deposit formation. One of the methods to control pitch deposition in the pulp and paper industry is the use of the talc. The talc acts primarily by a detackification mechanism and hence must be part of the deposit to control further deposition. The effectiveness of talc as control agent depends on its structural and surface characteristics, e.g. specific surface, surface energy, surface charge and ratio lypophilic/hydrophilic surface, being these related to its mineral composition and the thermal and surface treatments it has undergone. Five commercial talcs, corresponding to two groups of different mineralogical compositions, have been tested to determine their detackification capacity using the deposition tester developed by the Complutense University of Madrid. In this method, the quantification of the deposits is carried out by an image analysis (IA) of stainless steel collectors on which the deposit has formed. After IA a qualitative analysis to determine the deposit organic fraction is carried out by gas chromatography (CG) after deposit extraction.

The detackification capacity is expressed as the reduction of the deposits formed on the collectors when the different talcs at several concentrations are added to the pulp suspensions. The results show that pitch detackiness by talc addition is related to talc concentration and surface properties of mineral, as for example chlorite proportion, surface area and surface treatment and to the adsorption capacity of pitch on talcs. The general conclusions are that the talc having the highest quantity of mineral talc presents the best detackification capability and 
that all talcs studied have an appreciable detackification reduction at low proportion of addition.

Keywords Detackiness; deposit formation; dissolved and colloidal material; papermaking; paper recycling; pitch, pitch control; pulp; talc; wood extractives

\section{INTRODUCTION}

Wood pitch is released from fibres into process water during the production of thermomechanical pulp (TMP). The dispersion of pitch takes the form of colloidal droplets with a hydrophopic core, composed mainly of steryl esters and triglycerides, and a thin surface layer of sterols, fatty acids and resins acids (1-3). The changes of $\mathrm{pH}$ and salt concentration (ionic force) produced during bleaching, the oxidant treatment stages and the extraction stages produce the destabilization of dissolved and colloidal matter from the pulp extractive, forming sticky deposits called p̃pitchò (4). The characteristics of the wood pitch including hidrophobicity, deformability, tackiness, low surface energy, can cause deposition problems, decreasing the final product quality and the efficiency of papermaking process (5). The tendency of organic material to form deposits is related to its nature, and therefore to its tackiness. Tack is defined as the stickiness of a particle, qualitatively determined by touch. More specifically, tack is the energy required to separate two particles no permanently bound together. Nowadays, one of the technologies commonly used to control pitch deposition is the detackification. The detackification technology involves eliminating the tackiness associates with the pitch, but also may stabilize pitch particles preventing their agglomeration $(6,7)$.

Talc is one of the additives used traditionally for pitch control (7). Guerá (8) propose that, in the mechanism of detackification, the talc become incorporate in pitch deposits, which cause a decrease in tackiness and inhibits further deposition. Guerá theorized the existence of a second step after the adsorption of pitch onto talc (8). This second step occurs when talc particles with adsorbed resins form ñsandwich structuresò with very thin intercalates 
1 constituting a sort of nano-composite material. The dectakification occurs firstly through

2 immobilization of the sticky materials (9).

3 The term ñtalcò only describes a mineral on generic way while in the market it is possible to

4 find talc products with different mineralogical compositions and surface properties. Talc is a 5 mineral composed of hydrated magnesium silicate with the chemical formula $6 \mathrm{Mg}_{3} \mathrm{Si}_{4} \mathrm{O}_{10}(\mathrm{OH})_{2}$. The main or basal surfaces of this elementary sheet do not contain hydroxyl groups or active ions, which explains talc hydrophobicity and inertness. Highly lamellar talcs have large individual platelets whereas in a compact (microcrystalline) talc platelets are much smaller. The elementary sheets are stacked on top of one another, like flaky pastry, and because of the binding forces (Van der Waal's forces) linking one elementary sheet to its neighbors are very weak, the platelets slide apart at the slightest touch, giving talc its characteristic softness $(10,11,12)$. In various studies, the water contact angle has been found to be $66 \ddot{1} 90^{\circ}(7)$.

In this paper the capacity of different talcs, modified or not, used as a pitch dectackification agents has been studied by the measurement of the deposition tendency of water containing extractives. For this, $\mathrm{CaCl}_{2}$ has been added in order to get an approach to the real destabilization conditions that occur as consequence of the presence of $\mathrm{Ca}^{2+}$ in process waters in papermaking. The deposits have been measurement by means of the deposition tester developed by the UCM research group. On the other hand, the efficiency of the talcs on the extractives reduction was measurement by GC analysis.

\section{EXPERIMENTAL}

\section{Characterization of talcs}

Five commercial talcs have been used. The talcs correspond to two groups of different mineralogical compositions: A, with high concentration of talc and some dolomite; and B, with medium concentrations of talc and chlorite. The A group is formed by a natural talc (A) 
1 and anionic (A-T) and cationic (A-K) talcs modified superficially. The B group is formed by a 2 natural anionic talc (B) and modified cationic talc (B-K). Theses talcs have been characterized

3 by X Ray Diffraction, Scanning Electron Microscopy and Analysis by Dispersive Energies,

4 Zeta Potential and surface area measurements. The analysis showed that the type of chlorite

5 present in the talc B was Clinochlore. The Zeta Potential was determined with the Mütek PCD

603 device (at $\mathrm{pH}$ 7) and particle size distribution was determined by Sedigraph 5100 (13). The

7 mineralogical composition measured by X Ray Diffraction of both talc groups is shown in

8 table 1 . The physic properties are summarized in table 2.

9

Table 1.- Mineralogical composition of talcs (\%)

\begin{tabular}{|c|c|c|c|c|c|}
\hline & \multicolumn{3}{|c|}{ GROUP A } & \multicolumn{2}{|c|}{ GROUP B } \\
\hline & $\mathbf{A}$ & $A-T$ & A-K & B & B-K \\
\hline Talc (1), $\mathrm{Mg}_{3} \mathrm{Si}_{4} \mathrm{O}_{10}(\mathrm{OH})_{2}$ & 85,4 & 82,4 & 94,3 & 61,7 & 55,7 \\
\hline Talc (2), $\mathrm{Mg}_{3} \mathrm{Si}_{4} \mathrm{O}_{11} \mathrm{nH}_{2} \mathrm{O}$ & 13,2 & 16,0 & - & - & - \\
\hline Dolomite, $\mathrm{CaMg}\left(\mathrm{CO}_{3}\right)_{2}$ & 1,3 & 1,5 & 4,2 & - & - \\
\hline Calcite, $\mathrm{CaCO}_{3}$ & - & - & 0,3 & - & - \\
\hline Quarz, $\mathrm{SiO}_{2}$ & 0,1 & 1,5 & 0,3 & 0,5 & 0,4 \\
\hline Clinochlore, $\mathrm{Mg}_{5} \mathrm{Al}\left(\mathrm{Si}_{3} \mathrm{Al}\right) \mathrm{O}_{10}(\mathrm{OH})_{8}$ & - & - & - & 37,0 & 42,1 \\
\hline Ferrous and calcium oxide, $\mathrm{Ca}_{2} \mathrm{Fe}_{7} \mathrm{O}_{11}$ & - & - & - & 0,9 & 1,8 \\
\hline
\end{tabular}

\begin{tabular}{cccccc}
\hline & \multicolumn{3}{c}{ GROUP A } & \multicolumn{2}{c}{ GROUP B } \\
\hline Talc & A & A-T & A-K & B & B-K \\
Specific area BET $\left(\mathbf{m}^{\mathbf{2}} / \mathbf{g}\right)$ & 12 & 14 & 12 & 8,5 & 8,5 \\
Density $\left(\mathbf{g} / \mathbf{c m}^{\mathbf{3}}\right)$ & 2.80 & 2.78 & 2.80 & 2.78 & 2.78 \\
Hardness $(\mathbf{M o h s})$ & 1 & 1 & 1 & $1-2$ & $1-2$ \\
Zeta potential $(\mathbf{m V})$ & -69 & -69 & +45 & -55 & +30 \\
$\mathbf{H}_{\mathbf{2}} \mathbf{O}$ adsorbed $(\%)$ & 15 at $120^{\circ} \mathrm{C}$ & $<1$ & 1 at $120^{\circ} \mathrm{C}$ & $>0,5$ & $>0,5$ \\
$\mathbf{p H}(\mathbf{d i s p e r s i o n ~} \mathbf{1 0} \%)$ & 9 & 8,5 & 9 & 9,5 & 9,5 \\
$\mathbf{d}_{\mathbf{5 0}}(\boldsymbol{\mu m})$ & 4,2 & 4,5 & 4,2 & 3,5 & 3,5 \\
\hline
\end{tabular}


group B talcs are composed by a high proportion of chlorite.

\section{Preparation of the extractive dispersions}

The colloidal dispersions of extractives were obtained by extraction of Eucalyptus globulus wood sawdust in pilot plant scale with acetone (30L), evaporation of the solvent and reextraction with hexane in order to increase the selectivity of lypophillic compound extraction, according to standard SCAN-CN 50:93 (14). Subsequently, the solvent was evaporated in a rotary evaporator. Colloidal dispersions were obtained after alkaline hydrolysis with $\mathrm{KOH}$ solution and a new extraction of lipophilic compounds with hexane. A concentrated solution of pitch in acetone was obtained by evaporation until a $3000 \mathrm{mg} / \mathrm{L}$ concentration. The pitch dispersions were obtained by dilution of this concentrated solution with distilled water.

\section{Preparation of the talc suspensions}

Talc suspensions were prepared at $5 \mathrm{wt} \%$ in Milli-Q water and stirred overnight at the natural $\mathrm{pH}$ in order to be used as slurry.

\section{Deposition experiments}

The depositions experiments were carried out with the deposition tester developed by the UCM Research Group and described in more detail in previous researches $(15,16,17)$. It consists of an axial flow propeller, a rotor assembly with open ends, and a cylinder support with removable steel foils as collector surfaces. The propeller creates a flow parallel to the outer steel foil. The sticky material is transferred to the outer cylinder surface due to the flow mechanism. On the inner cylinder surface, depositions occur via an impact mechanism.

The experiments were carried out at $50{ }^{\circ} \mathrm{C}$ for $2 \mathrm{~h}$ and the rotation speed of the rotor was 250 rpm. The beaker was filled with $1.8 \mathrm{~L}$ of pitch dispersion contained about $50 \mathrm{mg} / \mathrm{L}$ of extractives. The experiments were carried out at $\mathrm{pH} 8$. The talc concentrations used during the experimentation were 50,100, and $200 \mathrm{mg} / \mathrm{L}$. In order to know the performance of the 
1 different talcs, a blank trial without talc addition was carried out. $\mathrm{CaCl}_{2}$ was added 1 min after

2 the talc addition to obtain the maximum amount of pitch aggregates to study in the deposition.

3 The pitch droplets are susceptible to an electrolyte-induced aggregation with $\mathrm{Ca}^{2+}$ that led to

4 the formation of deposits. The concentration of $\mathrm{Ca}^{2+}$ added was $10 \mathrm{mmol} / \mathrm{L} \mathrm{of} \mathrm{Ca}^{2+}(18 ; 19)$.

5 When the deposition experiment was finished, the stainless steel foils with the deposits were

6 withdrawn from the cylinder support and dried at room temperature before scanning with a

7 commercial computer flatbed scanner (HP Scanjet 6100C) at $600 \mathrm{dpi}$. The resulting scanned

8 images were analysed using the image analysis system ñStickies Measurement Systemò,

9 developed by the British Research Centre PIRA International and the UCM. The results are

10 expressed as follows: covered area of deposits expressed as $\mathrm{mm}^{2}, \mathrm{~mm}^{2}$ of deposits per $\mathrm{m}^{2}$ of

11 surface (ppm) and percentage of covered area of deposits (\%). In this paper, the sum of the internal and external deposits, expressed in $\mathrm{mm}^{2}$, (total deposits) are shown, representing the deposition on the entire collector. Therefore the reduction of the depositability by IA is obtained by the equation 1 .

Reduction $(\%)=\frac{\text { Total deposits without talc }\left(\mathrm{mm}^{2}\right)-\text { Total deposits with talc }\left(\mathrm{mm}^{2}\right)}{\text { Total deposits without talc }\left(\mathrm{mm}^{2}\right)} \times 100$

\section{GC analysis}

The analysis of extractives was carried out by a chromatograph Varian 3800 GC with a detector FID, coupled with a Varian 8200 Autosampler and with injector for liquids 1079 Universal Capillary Injector. The capillary column has a $15 \mathrm{~m}$ length and a 0,53 mm diameter and a film thickness $0,15 \mathrm{~m}$. The chromatograph was programmed from $100^{\circ} \mathrm{C}(0,5 \mathrm{~min})$ to $340^{\circ} \mathrm{C}$ at a rate of $12^{\circ} \mathrm{C} / \mathrm{min}$. The injector was programmed from $100^{\circ} \mathrm{C}(0,5 \mathrm{~min})$ to $340{ }^{\circ} \mathrm{C}$ at $200^{\circ} \mathrm{C} / \mathrm{min}$. After the experiment, the steel foils were removed and extracted with a solution of MBTE $(40 \mathrm{~mL})$ and acetic acid $(1 \mathrm{~mL})$ in an ultrasonic bath. Lypophilic extractives were silylated and determined by GC (20). 
1 Lypophylic extractives in water were determined by extraction with MBTE and analysis by

2

$6 \quad S C G\left(m m^{2}\right)=\frac{B S I\left(m m^{2}\right)}{B S G(m g)} x S M G(m g)$
$24 \quad K=\frac{B S I\left(m^{2}\right)}{B S G(m g)}$ 
2 According to this hypothesis, equation 2 can be formulated as:

$3 \quad S C G=K \times S M G$

4 obtained from equation 5 .

Figure 1. Experimental protocol

\section{RESULTS AND DISCUSSION} justifies the need to use a pilot plant extractor.

With this mathematical treatment, the total deposits measured by GC are expressed as square millimeters. On the other hand, the reduction of the depositability measured by GC is

$\operatorname{Re}$ duction $(\%)=\frac{\text { Deposited pitch without talc }\left(\mathrm{mg} \mathrm{m}^{-2}\right)-\text { Deposited pitch with talc }\left(\mathrm{mg} \mathrm{m}^{-2}\right)}{\text { Deposited pitch without talc }\left(\mathrm{mg} \mathrm{m}^{-2}\right)} \times 100$

As a summary, the figure 1 shows the schematic representation of the experiments carried out.

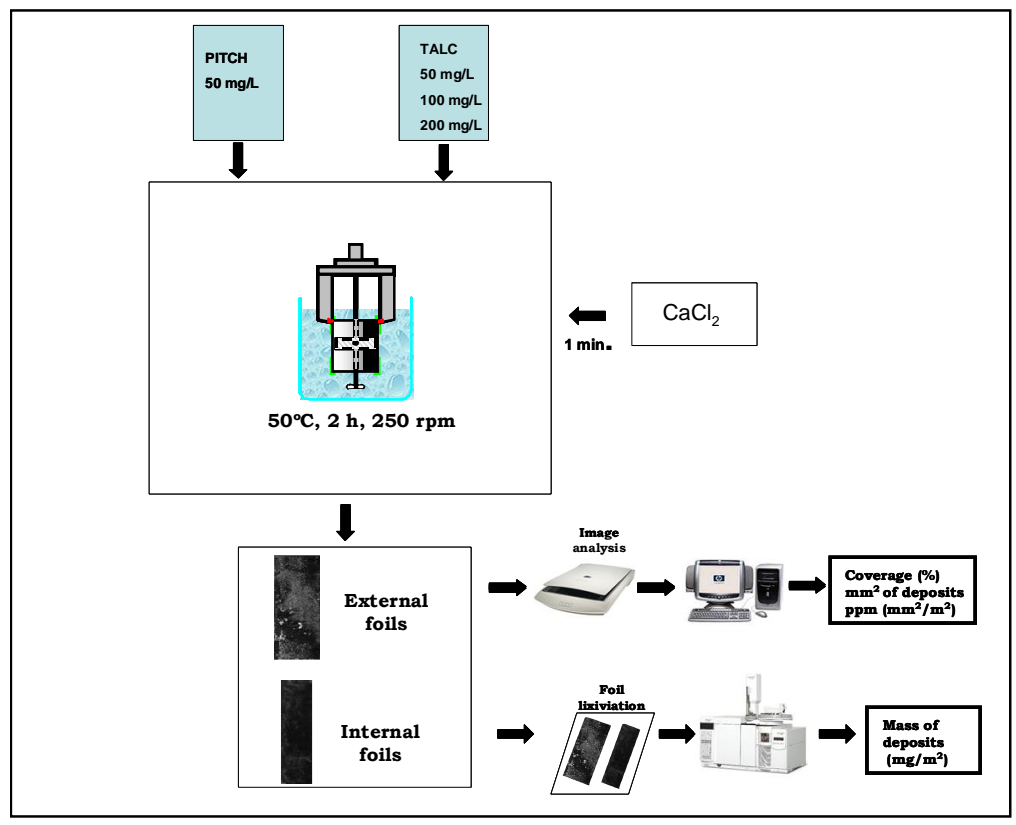

The results of the extractive characterization and the composition of the lypophilic fraction determined by GC are shown in table 3. The extractive content of the Eucalyptus globulus wood used in this experimentation is very low comparing with other genus species. This 
Table 3. Composition of Eucalyptus globulus extractives.

\begin{tabular}{ccc}
$\begin{array}{c}\text { Total extractives } \\
(\%)\end{array}$ & $\begin{array}{c}\text { Total } \\
\text { lypophilic } \\
\text { fraction }(\%)\end{array}$ & $\begin{array}{c}\text { Lypophilic } \\
\text { fraction on } \\
\text { total } \\
\text { extractives }(\%)\end{array}$ \\
\hline $0,75 \pm 0,5$ & 0,10 & 13,50 \\
\hline
\end{tabular}

The composition of the lypophilic fraction was $33 \%$ of sterol esters, $8 \%$ of triglycerides, $17 \%$ of fatty acids and $42 \%$ of sterols (13). The figure 2 shows the total deposit obtained with the addition of different talc concentrations of the A group, by IA and by GC, respectively. In all cases, the amount of deposits decreases with respect to the blanks when talc was added.
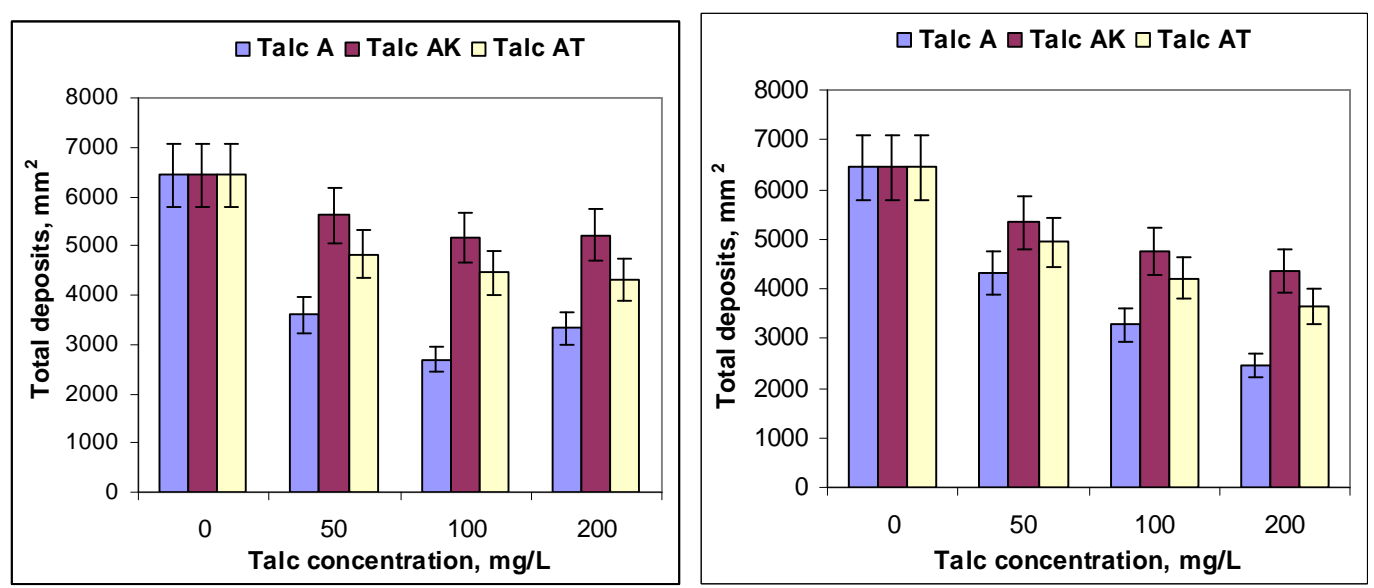

Figure 2. Total deposits obtained with the addition of group A talcs by IA and GC..

The results obtained with the two deposits determination techniques employed in the study showed slightly different trends. The deposits obtained by the deposition rotor and analysed by IA show a slightly higher degree of deposition than the obtained by GC analysis. The results measured by GC shown a regular decrease of the deposits with the addition of talcs. Both IA and CG analysis show that the lowest amount the deposits was achieved with talc A. 
1 The best performance obtained with this talc was at $100 \mathrm{mg} / \mathrm{L}$ according to the measurements

2 performed with IA, and $200 \mathrm{mg} / \mathrm{L}$ when using CG. Figures 3 shows the difference between the reduction results obtained by IA and by GC for the talcs A studied. The ordinate axis represents the decrease of the property considered as a reduction percentage of the formed deposits or as a percentage of pitch retained by adsorption on talc.

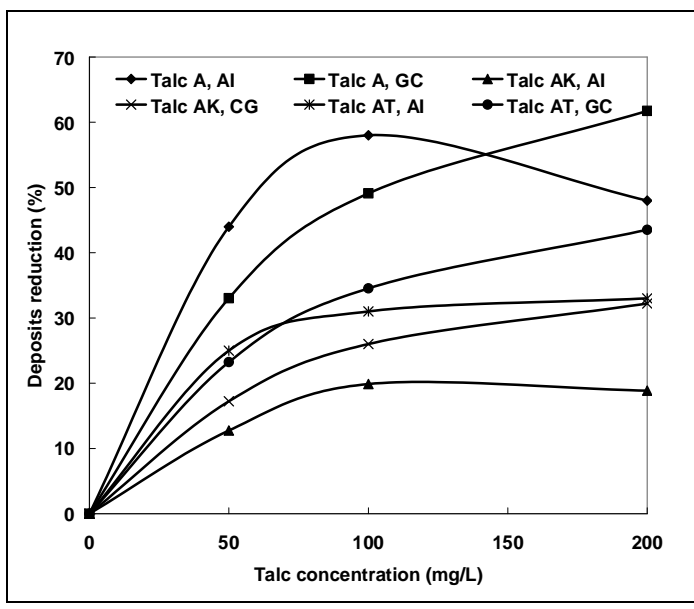

Figure 3. Deposition reduction versus talc concentration by IA and by GC for A group talcs.

The talc A depositions reductions measured by IA present a maximum of $57 \%$ at $100 \mathrm{mg} / \mathrm{L}$ of talc concentration and decrease at $200 \mathrm{mg} / \mathrm{L}$. A similar tendency was shown in all talcs when depositability reduction was determined with IA except with talc AT, which shows a slight increase in the reduction of deposit at $200 \mathrm{mg} / \mathrm{L}$

These results indicate that the initial hypothesis that the mass of extractives are proportional to the covered surface is only an approximation; the main deviation from this hypothesis could be due to talc deposition.

The highest detackification capacity was shown by talc A, high talc mineral grade, with a deposits reduction effectiveness obtained by GC of $62 \%$. This reduction of deposits, with initial pitch concentration of $50 \mathrm{mg} / \mathrm{L}$ and talc addition of $200 \mathrm{mg} / \mathrm{L}$, is significant since it reduces the accumulative effect of pitch in the recirculation water. 
1 Talc AK (high mineral grade cationized talc) presents a similar mineralogical composition to

2 A talc, although it differs in its surface properties. The superficial nature of this cationic talc is

the result of a treatment by adsorption with a cationic polyelectrolyte such as poly-diallyl-di methyl ammonium chloride (polydadmac). The reduction of deposits reached using talc AK was only $32 \%$ by CG. The lower detackificacion capacity of cationized talc AK could be explained assuming that the presence of cationic charges does not increase the affinity of talc to lipophilic compounds. The presence of cationic groups, such as quaternary ammonium salts of polydadmac, would form a layer of water molecules attached to the polyelectrolyte though their negative polar charges that it partially occupies along with the adsorbed molecules of polyelectrolyte.

The superficial nature of talc can be modified by heat treatment, as in the talc AT, keeping its mineral composition similar to talc A. These treatments increase its strong affinity for many types of organic molecules and its strongly hydrophobic and low influence on the overall distribution of micropores and mesopores in the particles of talc. However the inner surfaces created with these treatments are not accessible to the micelles of colloidal pitch. The formation of deposits reduction effectiveness obtained by GC dropped from $62 \%$ in the talc A to $44 \%$ with the AT. This latter talc is best for other applications as rheological control agent in liquid, resins, plastisols and adhesives and whitening reinforcing filer and processing aids in elastomers and plastics. The adsorption capacity of colloidal pitch over the talc AT is comparable to that of talc A.

The figure 4 shows the results obtained with the addition of different talc concentrations of the B group. 

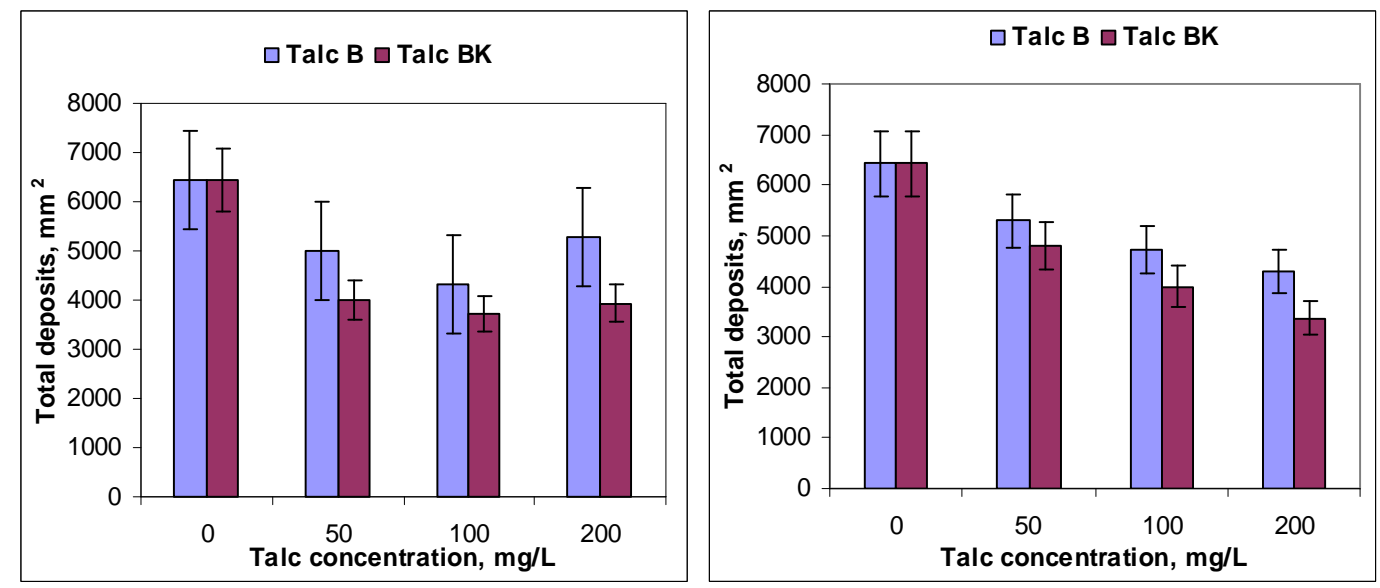

Figure 4. Total deposits obtained with the addition of group B talcs by IA (left) and GC (right).

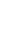

In this case, the lowest deposition was obtained with talc BK. This talc was the second best of the five talcs studied. The best performance obtained with this talc was at $100 \mathrm{mg} / \mathrm{L}$ according to the measurements performed with IA, and $200 \mathrm{mg} / \mathrm{L}$ when using CG. In IA the deposits obtained at $200 \mathrm{mg} / \mathrm{L}$ show an increase of the deposits detected. At high talc concentration, a part of the deposits detected by IA seems to be formed by talc, whereas with GC, only pitch deposits were detected, that is the reason for the increase of the deposits at talc concentration of $200 \mathrm{mg} / \mathrm{L}$. This increase of the deposits was not detectable by gas chromatography. Figure 5 shows the difference between the results obtained by IA and by GC for B talcs studied.

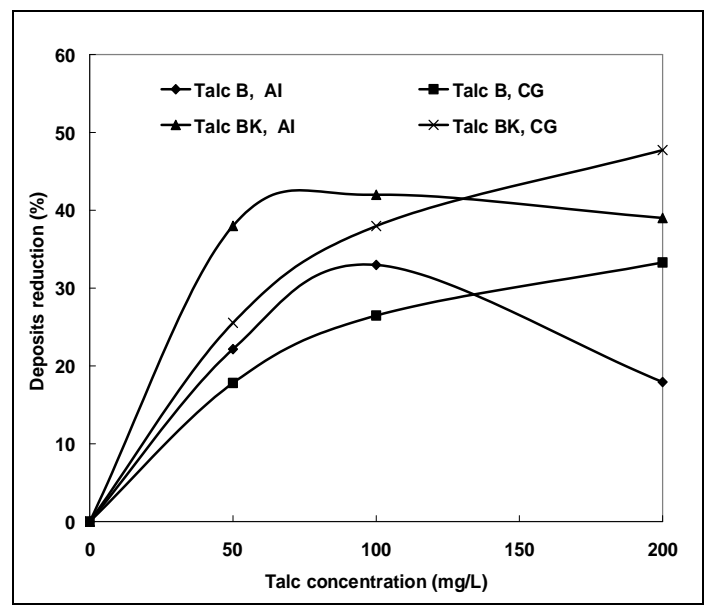

Figure 5. Deposition reduction versus talc concentration by A and by GC for B group talcs. 
1 The depositability reduction achieved with talc B reached $33 \%$ at the highest concentration of 2 talc studied, i.e. $200 \mathrm{mg} / \mathrm{L}$ measured by GC, a significantly lower value than that obtained

3 with talc A. The reduction of the deposits with the cationized talc BK reaches higher values, 4 up to $48 \%$ with the BK talc concentration of $200 \mathrm{mg} / \mathrm{L}$ by IA. These results imply that 5 detackificacion is not only based on the adsorption on talc, but also on other phenomena such 6 as the degree of readiness of talc to disperse in water. Talcs with a high content of chlorite can be dispersed better in aqueous medium than talcs having a higher mineral talc concentration; cationized talcs can be dispersed better in aqueous medium than unmodified talcs and these latter better than heat-treated talcs. Dectakification increases with the proportion of colloidal pitch fixed on the surface of talc and with the capacity of talc to maintain this dispersion. Due to its larger hydrophilic surface and the polar water adsorption to the positive charges of polyelectrolyte talc BK is the one having the highest capacity to disperse of the talcs studied. As summary, figure 6 shows the deposits reduction capacity of $200 \mathrm{mg} / \mathrm{L}$ of talcs in $50 \mathrm{mg} / \mathrm{L}$ of pitch dispersion, calculated by GC and IA.

The highest deposition reduction was obtained by GC analysis. The tendency of the reduction 
1 the highest deposition reduction with both analysis techniques. The second best de position reduction was obtained with the talc B-K, surface modified talc with high contents in chlorite.

\section{CONCLUSIONS}

The talcs studied have a high dectackification capacity in the paper and pulp mills waters even to low pitch concentrations. The detackification capacity of talcs can be attributed to two effects:

- The capacity to retain pitch on the lipophilic surface of talcs resulting in colloidal adsorption phenomena.

- The capacity of talcs to disperse in water.

Talc A was found to be the most effective talc to achieve the passivation of pitch due to its high lipophilic surface. Talcs having a higher content in chlorite show a lower surface lipophilic character, but a better dispersion capacity in water due to the higher proportion of polar surface. The use of these talcs may be more effective if the goal is the passivation of pitch to prevent pitch deposition on equipment surfaces. Cationic talc BK, with low mineral talc composition and positively charged surface, is the second best talc in detackiness capacity. Its high detackiness capacity is due to its dispersion capacity. Talc AT, with the high composition of mineral talc, has relatively less detackiness capacity, possibly due to its lower dispersion capacity.

At high talc concentrations, a low amount of talc was deposited in low turbulence areas (rotor outer foil deposition). This talc deposit, which is easily removed by flowing water shear forces, was obtained by AI analysis and was not detected by GC analysis.

\section{REFERENCES}

1-Saarimaa, V., Vähäsalo, L., Pranovich, A. and Holmbom, B., Nordic Pulp Paper Res. J. 21

(5): 93-98(2006). 
1 2-Blanco A., Negro C., Diaz L., Saarimaa, V., Sundberg, A., Holmbom, B., Appita J. $2 \quad 62(2): 113-117(2009)$.

3 3- Marques G, del Rio J. C., Gutierrez A., Bioresour. Technol. 101 (1): 260-267(2010).

4 4-Back, E. L. in Pitch Control, Wood Resin and Deresination (E. L. Back, and L. Allen, Ed) $5 \quad$ Tappi Press, Atlanta, 2000, Chap. 1.

6 5-Nguyen, D. T., TAPPI J. 81 (6): 142-151 (1998).

7 6- Hubbe, M.A., Rojas, O.J. and Venditti, R.A., Nordic Pulp Paper Res. J.21(2):154-171 8 (2006).

7- Wallqvist, V., Claesson, P. M., Swerin, A. Schoelkopf, J. C. and Gane, P. C., Colloids Surfaces A: Physicochem. Eng. Aspects. 277: 1831190 (2006).

8- Guerá, N. Shoelkopf, J. and Gane, P. A., Nordic Pulp Paper Res. J. 20 (2): 156-163 (2005).

9-Benecke, F., Gantenbein, D., Gane, P. A. C. and Gliese, T., Nordic Pulp Paper Res. J. 24 
$143(2000)$.

2 16-Monte, M. C., Blanco A., Negro C. and Tijero J., J. Chem. Eng. 105: 21-39 (2004).

3 17-Monte, M. C., MacNeil, D., Negro, C. and Blanco, A. Holzforschung 64: 277- 283(2010).

4 18-Otero, D., Sundberg, K. Blanco, A., Negro C. and Tijero, J., Nordic Pulp Paper Res. J. 5 15(5): 288-293 (2000).

6 19-Nylund, J., Sundberg, A. and Sundberg, K. Colloids Surfaces A: Physicochem. Eng. $7 \quad$ Aspects. 301 (1-3): 335-340(2007).

8 20-Örsa, F. and Holmbom, B., J. Pulp Paper Sci. 20 (12): 361-365 (1994). 